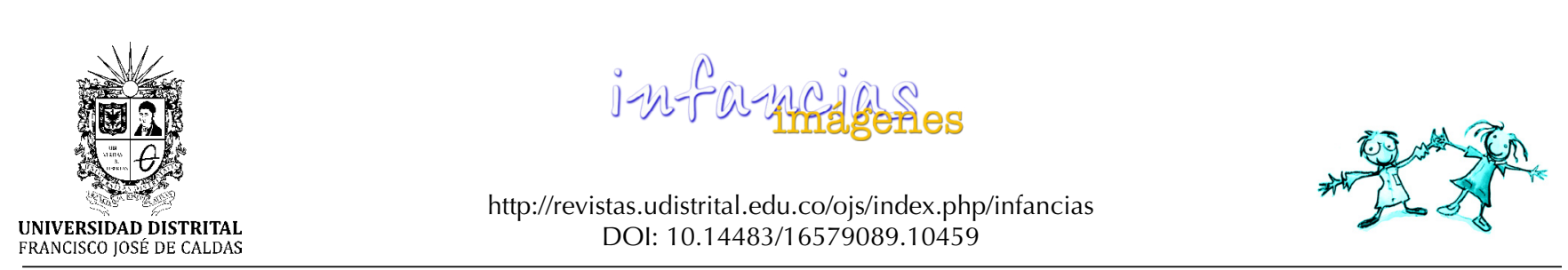

IMÍAENES DE INVESTIGACIÓN

\title{
Imaginarios sobre naturaleza: una experiencia con niños y niñas del barrio Londres*
}

\author{
Imaginaries on Nature: An Experience with Children from the Neighborhood Londres
}

Sergio Esteban Bonilla Castillo'

Para citar este artículo: Bonilla, S. E. (2017). Imaginarios sobre naturaleza: una experiencia con niños y niñas del barrio Londres. Infancias Imágenes, 16(2), 216-227.

\section{Resumen}

Este estudio, de tipo cualitativo descriptivo, indaga por los imaginarios sociales que sobre la naturaleza tienen los niños y niñas del barrio Ciudad Londres y en el que colaboran cuatro niños y dos niñas, de 9 y 10 años. Se buscó develar las significaciones imaginarias empleando como técnicas de recolección de información un taller iconográfico y una entrevista semiestructurada. Los niños y niñas han vivido experiencias estrechas con la naturaleza y han vivenciado prácticas tradicionales campesinas en sus hogares o su barrio, relación que les suscita emoción y alegría. La mayoría de imaginarios identificados obedecen a lo instituido, alimentados por discursos provenientes de la escuela, la televisión y la familia, instituciones que influyen significativamente en la construcción de imaginarios de los niños y niñas. Se evidencia, en pequeña medida, un imaginario instituyente correspondiente a la comprensión de la existencia de organizaciones ecosistémicas autónomas que no son para servicio del ser humano.

Palabras clave: significaciones imaginarias; imaginarios instituidos; imaginarios instituyentes; ecopedagogía.
Recibido: 23-mayo-2016 / Aprobado: 09-junio-2016

\begin{abstract}
This document presents the results of a Descriptive-Qualitative research about Social Imaginaries on Nature, in six children of ages 9 to 10, from a specific neighborhood of Bogotá: Ciudad Londres, which is located in a Natural reserve. It sought to unveil the imaginary meanings using techniques such as collection of information a workshop iconographic and a semi-structured interview. Children have experienced close experiences with nature and have experienced traditional countryside practices in their homes or neighborhoods, a relationship that causes emotion and joy. The majority of the imaginary identified, obey the instituted, fuelled by speeches from the school, television and family, institutions that significantly influence the construction of imaginaries children. There is evidence, to a small extent, an imaginary institute corresponding to the understanding of the existence of autonomous ecosystemic organizations that are not for the service of the human being.
\end{abstract}

Keywords: imaginary significations; instituted imaginaries; instituting imaginaries; education for sustainability.

\footnotetext{
* Estudio realizado en la ciudad de Bogotá entre mayo de 2015 y febrero de 2016 para la obtención de título de la Especialización en Infancia, Cultura y Desarrollo, Universidad Distrital Francisco José de Caldas; bajo la dirección de la doctora Cecilia Rincón Verdugo.

1 Licenciado en Química; Especialista en Infancia, Cultura y Desarrollo, de la Universidad Distrital Francisco José de Caldas. Laboratorista, División de Laboratorios, Universidad Militar Nueva Granada. Correo electrónico: sergio.bonilla@unimilitar.edu.co
} 


\section{Introducción}

Hoy día se conocen las problemáticas ambientales que las dinámicas sociales y económicas han generado debido a una filosofía de vida del ser humano basada en el abuso indiscriminado de la naturaleza vista como recurso. Problemáticas como las sequías, el calentamiento global, la extinción de las especies animales y vegetales, entre otras, son resultados exclusivos de la manera en que el ser humano ha decidido relacionarse con su entorno. Dicha relación no solo se produce a nivel macro, sino que se evidencia en la cotidianidad, en la que los seres humanos se han vuelto reproductores de prácticas inconscientes que contribuyen a la depredación y al malgasto irracional de lo natural como recurso y que tiene que ver con el estilo de vida de cada persona. Como menciona José Eustaquio Romão "las amenazas que se ciernen sobre el planeta no se construyeron naturalmente sino de las intervenciones históricas humanas, de carácter irresponsable y carentes de ética" (2002, p. 15). En las ciudades, la producción excesiva de polímeros, la emisión de gases del efecto invernadero, el mal manejo de los residuos, la contaminación de las fuentes hídricas, entre otras, se han normalizado en nuestra vida al punto que no hay un cuestionamiento de las acciones cotidianas de la gente del común.

En la ciudad de Bogotá se evidencian problemáticas como inundaciones, contaminación en muchos ríos y quebradas, además de los altos niveles de gases del efecto invernadero emitidos al ambiente por el tráfico y la industria. Sumado a lo anterior, muchas calles de la ciudad se ven sucias y lucen como desiertos de asfalto donde son muy pocos los árboles que permanecen en pie.

Tomando entonces a Bogotá como macro-contexto del presente estudio, es importante anotar que su gran extensión y la diversidad geográfica y socioeconómica que abarca nos obliga a analizarla como un conjunto de diversos sectores, por lo que es preciso destacar que gran parte de la población que vive al oriente de la ciudad lo hace sobre las montañas mientras que, en el occidente los habitantes están ubicados en la sabana, cuestión que genera una amplia gama de micro-contextos con múltiples variaciones de las cuales este estudio trabajó uno específico.
El barrio Ciudad Londres en la ciudad de Bogotá se encuentra ubicado en la parte alta del sur oriente de la ciudad; se caracteriza por pertenecer al estrato socioeconómico 1. Además, muestra características hibridas entre la ruralidad y la urbanidad en donde aún se evidencian prácticas campesinas como el pastoreo y la siembra y se ubica en la entrada del páramo de Cruz Verde, dentro del parque natural Entrenubes, lo que hace que esta población tenga una relación cercana con este ambiente natural con unas particularidades como su clima, altura y su cercanía a ciertas especies animales y vegetales propias del páramo.

Se tomó como población participante un grupo de niños y niñas de este sector, escolarizados en instituciones públicas del sector, con edades entre 8 y 10 años. Se tiene en cuenta la importancia de su voz y acciones en la sociedad pues hacen parte activa de ella, además de jugar un papel de gran importancia en la continuación o transformación de las dinámicas generales de tal sociedad. El niño y la niña "participa activamente en la construcción de su propio conocimiento y en el de los otros, interactúa con el otro, desde el momento en que es engendrado y es capaz de generar importantes cambios mentales, paradigmáticos y sociales" (Santamaría y Bothert, 2011, p. 68).

Como objetivo general se plantea indagar cuáles son los imaginarios que se evidencian, en los niños y niñas del barrio Ciudad Londres, acerca de la naturaleza y su relación con la misma.

\section{Los imaginarios sociales}

La teoría del imaginario social aparece en una época de culturas rígidas en la que primaban las concepciones de ser humano y recursos ligados a los sistemas de producción existentes, en ese momento los sistemas político-económicos comunista y capitalista. El concepto de Castoriadis se abre camino abruptamente entre los paradigmas de pensamiento reinantes mostrando cómo es la sociedad productora y producto, a la vez, de su realidad pasada, inmediata y futura y cómo los individuos de esta sociedad, como seres históricos-sociales, se construyen bajo estructuras instituidas, pero además son quienes les dan vida a dichas estructuras como reproductores en su accionar cotidiano. En palabras de Castoriadis: 
[...] lo social-histórico es lo colectivo anónimo, lo humano impersonal [...] que ciñe cada sociedad entre las demás y las inscribe a todas en una continuidad en la que de alguna manera están presentes los que ya no son, los que quedan por fuera e incluso los que están por nacer. Es, por un lado, unas estructuras dadas, unas instituciones y unas obras "materializadas", sean materiales o no y, por otro lado, lo que estructura, instituye, materializa. (1983, p. 11)

Vemos, entonces, que es la misma sociedad la que a través de su devenir histórico ha dado vida a su cultura, instituciones y acuerdos a los que no está el ser humano pasivamente atado, en cuanto a individuo, más no como grupo de individuos. Es decir, cada individuo crece y se desarrolla dentro de un conjunto de acuerdos sociales que le dan forma como sujeto histórico-social. Pero dichos acuerdos, pese a ser rígidos y de una gran fuerza y cohesión, no son inmanentes y pueden verse alterados únicamente por ese mismo sujeto cuando, en conjunción con otros, ha vivido un proceso que lo ha llevado a la transformación interna y, por tanto, al replanteamiento de su relación cotidiana con la sociedad. Son estas alteraciones del curso de lo social las que quedan inscritas en la historia al romper con la inalteridad y la linealidad y pasar a ser denominadas un hecho histórico.

Lo instituido y lo instituyente en lo imaginario Castoriadis (1983) analiza la historia en relación con lo imaginario y resalta que lo que queda inscrito en la historia tiene que ver con sucesos que marcaron diferencias, que llevaron al cambio de la linealidad de lo que venía ocurriendo. Alteraciones de la continuidad de los acuerdos sociales en un determinado contexto que se hacen dignas de ser recordadas, al tiempo que su transformación perdura y da lugar a una realidad alterada de lo que venía siendo: la modificación histórico-social de lo instituido producida por la emergencia de lo instituyente.

Ahora, si la realidad histórica-social obedece a esa tensión entre lo instituido y lo instituyente, es posible analizar, de las sociedades contemporáneas, cómo se ha construido la actual relación entre el ser humano y su entorno natural hasta obtener el preocupante panorama de nuestros días.

\section{Las significaciones imaginarias}

[...] Las significaciones no son evidentemente lo que los individuos se representan, consciente o inconscientemente, ni lo que piensan. Son aqueIlo por medio de lo cual y a partir de lo cual, los individuos son formados como individuos sociales, con capacidad para participar en el hacer y en el representar decir social, que pueden representar, actuar y pensar de manera compatible, coherente, convergente incluso cuando sea conflictual. (Castoriadis, 1983, p. 370)

Desde esta definición de Castoriadis sobre las significaciones imaginarias podemos identificarlas, entonces, a través manifestaciones propias y naturales de los sujetos que corresponden a un lenguaje (representar-decir) y un hacer identitario-conjuntista y que hacen parte del individuo mismo como ser social. Las significaciones imaginarias se pueden encontrar en el lenguaje o la acción de los sujetos que de manera inconsciente permiten emerger creencias, ideas, afectos, imágenes, entre otros, que llevan en sí una posición o se posicionan en un punto que es siempre en relación con el mundo social instituido.

\section{Imaginarios instituidos sobre la naturaleza}

Mucho se habla de la cuestión ambiental en todos los escenarios de la sociedad contemporánea. Hoy en día, a través de la escuela y los medios de comunicación, se promulgan discursos en pro de un sentido ecologista y de acciones frente al cuidado del medio ambiente y esto se debe a las políticas ambientales que han surgido hace no más de 20 años. Pero, pese a todos los esfuerzos que se han puesto en las agendas nacionales e internacionales, los sujetos de las distintas sociedades continúan repitiendo prácticas inadecuadas de relación con los entornos naturales lo que resulta en la continuidad de la depredación y deterioro del planeta. Tal parece que dichas agendas son estáticas y no se conectan con discursos y prácticas de la vida cotidiana de los individuos que ven a diario en los medios diversas contradicciones 
en el tema cuando, por un lado, las noticias dan cuenta de los desastres y abruptos cambios a nivel climático y ambiental en general y, por el otro, les llueve publicidad que los invita a consumir y alimentar el sistema de producción que está marcando un serio desequilibrio con el planeta como el gran ambiente natural. El ser humano parece concebir el cuidado ambiental en distante relación con su propio bienestar, pareciera ser que para relacionarnos mejor con el planeta creemos necesario sacrificar nuestro estilo de vida o estado de confort pues "nunca conseguimos librarnos enteramente de esta visión del ambientalismo como algo opuesto a las necesidades humanas inmediatas" (Jay Gould, citado por Gadotti, 2002, p. 53). Lo anterior hace referencia a un problema más profundo que aquel que tiene que ver con la simple conservación y preservación de los entornos naturales y es que, como lo que plantea Leff, "la cuestión ambiental, más que una problemática ecológica, es una crisis del pensamiento y del entendimiento, de la ontología y de la epistemología con las que la civilización occidental ha comprendido el ser, a los entes y a las cosas" (2007, p. 12).

\section{Algunos imaginarios instituyentes sobre naturaleza}

El bien común no es algo exclusivamente humano, sino de toda la comunidad cósmica. Todo cuanto existe y vive merece existir, vivir y convivir. El bien común particular surge partiendo de la sintonía y sinergia con la dinámica del bien común planetario y universal. (Boff, 2013)

Pensar en identificar e interiorizar lo instituyente, en la cuestión ambiental, se convierte en imprescindible bajo el panorama actual tras años de inalteridad de una instituida manera de relación con lo natural que devasta la vida del planeta en todos sus niveles y nos pone en riesgo de autodestrucción. Son varios y diferentes profesionales que en diferentes momentos han empezado a alimentar, con sus estudios y reflexiones, un nuevo paradigma frente a la relación con lo natural.

El libro Pedagogía de la Tierra de Moacir Gadottti reúne diferentes elementos que se pueden entender como instituyentes en este sentido. El autor establece dos categorías de lo que él denomina pedagogía de la Tierra: la planetariedad y la sustentabilidad, con las cuales se puede comprender un nuevo sistema relacional del ser humano con todo lo natural bajo una visión del planeta como una totalidad compleja físico-biológica-antropológica de la que hacemos parte.

La ecopedagogía propone que para que las sociedades logren una nueva manera de relacionarse con los entornos naturales es necesario construir una nueva mirada, desde la educación, en los sujetos y las sociedades, bajo los siguientes principios:

\section{[...] -El planeta como única comunidad}

-La Tierra como madre, organismo vivo y en evolución -Una nueva conciencia que sabe lo que es sustentable, lo que es apropiado, lo que tiene sentido para nuestra existencia.

-Nuestro hogar es la Tierra.

-Una pedagogía biófila (que promueva la vida): involucrarse, compartir, relacionarse, entusiasmarse.

-Una concepción del conocimiento que admite solo ser integral cuando es compartido.

-Un caminar con sentido (vida cotidiana).

-Una racionalidad intuitiva, afectiva y comunicativa más no instrumental.

-Cultura de la sustentabilidad. (Gadotti, 2002, p. 152)

La naturaleza ante el imaginario de desarrollo de la sociedad colombiana

La sociedad actual se relaciona con la naturaleza de una manera instrumentalista donde la utiliza para su interés de manera irracional e inconsciente. Esta relación con los entornos naturales está arrojando, como resultado, la devastación de nuestro propio hábitat y de lo natural, como aquella riqueza ecosistémica y viva que junto con los humanos es producto de miles de años de evolución biológica. En Bogotá se sigue construyendo en los cerros, talando bosques y desplazando a las especies animales; el apresurado crecimiento de la ciudad produjo la contaminación de los ríos que atraviesan la ciudad y que hoy en día son caños por donde corren las aguas negras.

Frente a esta problemática, Arturo Escobar hizo una investigación sobre la sociedad colombiana y su noción de desarrollo actual, encontrando que está establecida en "los reacomodos políticos que se dieron al final de la Segunda Guerra Mundial en 
los que, por medio de la misión Currie, se estipularon procederes requeridos para alcanzar rápidamente las formas de vida creadas por la civilización industrial" (Escobar, 1986, p. 17). De esta manera, el discurso dominante que promulgó la idea de desarrollo anclada a la industrialización, la urbanización, la explotación y producción en serie y la idea de progreso a costa de la depredación de la naturaleza, parece, se instituyó como imaginario político de nuestra sociedad.

Los significados, conceptos y el estilo de vida en que nos hemos desenvuelto, entonces, frente a los entornos naturales como sociedad "en constante desarrollo" están íntimamente entrelazados con la construcción de instituciones imaginarias que abarcan toda la cuestión social, de manera que la ética y pensamiento de los individuos se ciñe a dichas instituciones reproduciendo prácticas y discursos (instituidos) y anulando cualquier forma alternativa de pensamiento diferente (instituyente).

El presente trabajo pretende conocer, a través de los niños y niñas como protagonistas, cómo en un sector específico de la ciudad de Bogotá se ha instituido y se instituyen imaginarios sobre la naturaleza y la relación con ella.

Los niños y las niñas importantes actores sociales Han sido muchas las miradas que de la infancia han hecho las sociedades a lo largo de la historia. En la contemporaneidad es posible comprender el concepto de infancia, como lo menciona Rincón:

[...] como es hoy, con todas sus contradicciones, poniendo en diálogo las creencias e imaginarios de antaño con las nuevas concepciones que reconocen al niño como sujeto, ser del presente, con deseos, con razonamientos y diferentes formas de ver el mundo y de relacionarse con el adulto. (2007, p. 148)

Desde este punto de vista, y teniendo en cuenta al niño y la niña como sujetos de cultura y lenguaje, podemos comprender su importancia e incidencia en el rumbo del desarrollo de las sociedades a través de sus interacciones con el mundo pues:

[...] las interacciones tienen que ver con la manera como el niño se vincula a los otros, realizando mutuamente las actividades de su comunidad, haciendo parte de un tejido social que a su vez le ofrece las herramientas para poder llevar a cabo el proceso de apropiación de su cultura. (Santamaría y Bothert, 2011, p. 67)

La familia, concebida como núcleo de la sociedad, entra en un proceso de transformación alrededor de la llegada de nuevos miembros que incidirán en los espacios, rutinas y proyecciones a futuro. Al repetirse este fenómeno en múltiples familias de las comunidades se hace evidente la influencia de la infancia en las mismas, de forma que en una visión plausible de desarrollo humano y social no se pueden ver de manera aislada ninguno de sus elementos y esto incluye a la población infantil.

Esto sucede igualmente en sentido recíproco. Es imposible hablar del niño sin situarlo en un entorno social determinado, un contexto en el que desde antes de nacer vuelca sus sentidos y pensamiento para aprender las reglas del juego: símbolos, significados, estereotipos, entre otros, que quedan inscritos en su psiquis, y aprende entonces el ser social y el hacer social que determinarán en gran medida sus comportamientos y maneras de relación con la realidad: consigo mismo, con el otro y con el ambiente. Acerca de esto, Santamaría y Bothert afirman como los

[...] saberes infantiles se relacionan con la apropiación que hacen los niños del mundo externo, que se da inicialmente en el ámbito social, es decir, el niño comprende el mundo, construye sus conceptos y los utiliza sólo a través de la interacciones con los otros. (2011, p. 67)

Es en este proceso de aprehensión de lo social, y mediado por el lenguaje, donde el niño o la niña empieza a hacer una construcción de sus imaginarios sociales y con ellos se vuelve portador de prácticas y discursos instituidos, pero, además, es agente posibilitador de alteraciones histórico-sociales instituyentes.

\section{Metodología}

Este estudio se enmarca en el paradigma de la investigación social a la luz de la metodología de 
investigación cualitativa toda vez que esta se caracteriza porque "su preocupación no es prioritariamente medir sino descubrir textualmente y analizar el fenómeno social a partir de sus rasgos determinantes" (Bonilla-Castro y Rodríguez, 1997, p. 62).

Dentro de este marco de investigación social cualitativo se adoptó el enfoque interpretativo "que renuncia al ideal objetivista de la explicación y postula la búsqueda de la comprensión" (González, 2000, p. 232).

\section{Categorías de análisis}

Se plantea, en primera medida, lo instituido y lo instituyente sobre la naturaleza, buscando diferenciarlos. Lo instituido, según Castoriadis, corresponde a aquello que ya se ha establecido y aceptado socialmente, por lo que en el caso de naturaleza podemos identificar los imaginarios instituidos mediante expresiones comunes y conocidas frente a la relación con la naturaleza y pensamientos y posiciones conocidas frente a la relación con lo natural. Como imaginarios instituyentes sobre naturaleza podemos establecer algunas ideas que plantea Gadotti como principios de la ecopedagogía, y que en la sociedad actual no se han instituido:
- "El planeta como única comunidad

- La tierra como madre, organismo vivo y en evolución

- Una mirada biófila: involucrarse, compartir, relacionarse, entusiasmarse.

- Cultura de la sustentabilidad" (2002, p. 152).

Como otra categoría de análisis se plantean tipos de imaginarios frente a lo natural (tabla 1).

Una vez definidas las categorías de análisis se seleccionaron las técnicas e instrumentos con los que obtener los datos: el taller iconográfico y la entrevista semiestructurada

\section{Taller iconográfico}

En esta sesión los niños y niñas realizaron un ejercicio de recuerdo en el que, con los ojos cerrados, evocaban en detalle una experiencia en medio de un ambiente natural para posteriormente dibujarlo. Luego de realizado el dibujo, los niños lo explicaron y contaron más detalles de la experiencia dibujada.

\section{Entrevista semiestructurada}

Esta sesión se desarrolló como una conversación con los niños y niñas en la que se les preguntó

Tabla 1. Categorías de análisis: Tipos de imaginarios sobre naturaleza.

\begin{tabular}{|c|c|c|}
\hline Categoría & Comprende & Tipos de imaginario \\
\hline \multirow[b]{3}{*}{$\begin{array}{l}\text { Cómo ve, } \\
\text { inconscientemente, } \\
\text { el ser humano a la } \\
\text { naturaleza. }\end{array}$} & \multirow[b]{3}{*}{$\begin{array}{l}\text { Cómo concibe } \\
\text { el niño o niña al } \\
\text { ser humano en } \\
\text { relación con el } \\
\text { medio ambiente. }\end{array}$} & $\begin{array}{l}\text {-Dominancia racional: manifiesta comprender al ser humano como centro de la } \\
\text { vida en la que los demás elementos están a disposición de su dominio. }\end{array}$ \\
\hline & & $\begin{array}{l}\text {-De equilibrio: el ser humano es parte de un equilibrio dinámico con la } \\
\text { naturaleza y debe propender por ese equilibrio. }\end{array}$ \\
\hline & & $\begin{array}{l}\text {-Naturaleza deidificada: la naturaleza es superior al humano, debemos } \\
\text { agradecerle por todo lo que nos brinda. }\end{array}$ \\
\hline \multirow{3}{*}{$\begin{array}{l}\text { Relación con la } \\
\text { naturaleza ante la } \\
\text { conocida situación } \\
\text { de crisis ambiental. }\end{array}$} & \multirow{3}{*}{$\begin{array}{l}\text { El niño o niña } \\
\text { manifiesta } \\
\text { una forma de } \\
\text { pensamiento } \\
\text { sobre acciones } \\
\text { frente a la } \\
\text { realidad actual } \\
\text { de la naturaleza. }\end{array}$} & $\begin{array}{l}\text { "Volver al primitivismo: Aboga por volver a una vida no civilizada a través de la } \\
\text { desindustrialización, la abolición de la división del trabajo y el abandono de la } \\
\text { tecnología" (Ospina, 2008). }\end{array}$ \\
\hline & & $\begin{array}{l}\text { "Construir un ideal de eco-desarrollo: Imaginario asociado con una articulación } \\
\text { armónica entre el crecimiento económico y la naturaleza" (Ospina, 2008). }\end{array}$ \\
\hline & & $\begin{array}{l}\text { "Defensa del patrimonio común: buscan la protección y conservación de la } \\
\text { naturaleza (flora, fauna, otros recursos naturales) incitando a pensar que si } \\
\text { permanece lo que aún tenemos prevalece la vida humana" (Ospina, 2008). }\end{array}$ \\
\hline
\end{tabular}


por experiencias relacionadas con naturaleza que hubieran tenido en la escuela, en la casa y a través de la televisión y se indagó por lo que ellos y sus familias hacían por la naturaleza.

Los hallazgos de la investigación se obtuvieron mediante el empleo de dos métodos: el análisis iconográfico permitió obtener las significaciones imaginarias expresadas a través del dibujo y la voz del niño y de la niña explicándolo. Como segundo método, se realiza una sistematización de los datos a través de una rejilla en la que se obtienen las significaciones imaginarias y se identifican como instituidas o instituyentes.

\section{Análisis iconográfico}

Para analizar los productos del taller iconográfico se realizó el proceso de análisis planteado por Letorneau (2007), según el cual el proceso se divide en tres etapas:

En primer lugar, se realiza la nomenclatura del documento que consiste en una primera observación seguida de la "identificación de los componentes de la imagen" (p. 98). Luego de esto, se procede a hacer "la descripción del documento como un todo, planteándose como objetivo, percibir su significación de conjunto [...] lo cual se descubre cuando se identifican los vínculos que unen los elementos que han sido inventariados en la etapa precedente" (p. 99). En la contextualización "el documento iconográfico se vuelve objeto de cuestionamiento [...] así se integra a una red de relaciones cuya estructura conviene esclarecer" (p. 100).

\section{Resultados y análisis}

A continuación, se presenta la contextualización de las iconografías elaboradas por los niños y las niñas participantes del taller:

Niño participante $\mathbf{N}^{\circ}$ 1: plasmó una experiencia vivida en el páramo de Usme realizada por el colegio en el que estudia, que es un colegio público del sector. El viaje lo realizó con su tío, quien fue su cuidador. Relata la presencia de lo plasmado en el dibujo; acerca de las montañas manifiesta el recuerdo de haber podido ver su colegio, que queda ubicado en el otro páramo: Cruz Verde, hacia el suroriente. También sobre estas dice ser lo que más recuerda de esa experiencia. Manifiesta haber visto peces, haber pescado y comido mojarra, dice que "la mojarra se frita y queda rica", también dice que se metió y el agua era calientica. Al preguntarle cómo se sintió, dijo: feliz.

Niño participante $N .^{\circ}$ 2: el dibujo corresponde a una experiencia en la Mesa, Cundinamarca. El paisaje muestra claramente cosas que ella comprende como naturaleza y que pudo ver en su viaje. Menciona que en los árboles había frutas, que en el lugar donde se encontraban siempre pasaban palomas. Recuerda al perro mencionando que era chistoso y cuenta cómo bajaban naranjas de los árboles y el perro se las comía. Muestra gusto por las flores de colores y las representó en su dibujo.

Niño participante $N .^{\circ}$ 3: representa una experiencia vivida en el campo; en cuanto al agua ella mencionó que había peces, que ella algunas veces se bañaba allí y cogía los peces. De las montañas manifiesta haber subido en ellas y haber "visto todo el país" y parecerle muy bonito, luego agrega qué fue lo que más le gustó pues pudo ver muchas cosas que no conocía. Menciona como algo agradable haber podido alimentar a los caballos y las vacas. Cuando se le pregunta por lo que sintió cuando vivió esta experiencia contesta que mucha emoción y alegría. Luisa dibuja una jirafa en su dibujo y cuando se le pregunta dice que la dibujó porque es bonita y porque le gusta mucho.

Niño participante $N .^{\circ} 4$ : el dibujo hace referencia a una visita al páramo de Cruz Verde con su familia. Johan dibujó lo que vio allí de manera que menciona las montañas, muchos árboles entre los que vio uno con naranjas y uno con manzanas y el río, además de una lombriz y una araña. De las montañas menciona haber subido a ellas. Sobre el río dice que vio un pez. Johan menciona que allí acamparon, hicieron una comida y bajaron hasta por la noche. Cuando se le pregunta por el nombre que pondría a su dibujo contesta: las aventuras.

Niño participante $\mathbf{N}^{\circ}$ 5: realizó un dibujo de su viaje al páramo Cruz Verde en el que cuenta haber visto una cascada en la que pudo ver muchos peces. Menciona haber visto arboles con frutas: manzanas y duraznos. También vio un pájaro amarillo y dice de este que era de gran tamaño. Sobre la 
cascada le llamó la atención cómo sonaba el agua y los peces. Juan comenta que armaron carpa y realizaron una fogata. Menciona que pasaban muchos pájaros, palomas de color gris, blanco y negro. Al preguntarle que le agregaría a su dibujo menciona: montañas.

Niño participante $\mathbf{N} .^{\circ}$ 6: relata un viaje a Cota, Cundinamarca. Dice que dibujó una casa donde podían ir al río y que en este podían jugar, ver y coger los peces. Dice que podían coger frutas como guayabas y naranjas y esto lo plasmó en el árbol. Michael dice que no dibujó las vacas, pero manifiesta que podían ordeñarlas y alimentar los pollitos. Michael cuenta que había pájaros y eran de color negro. Cuenta que las montañas eran bonitas y que cuando estaba en el paseo se sentía emocionado y que lo que más le gustó fue ordeñar la vaca y alimentarla.

\section{Sistematización de la información}

En esta fase del análisis se realiza una rejilla en la que se explicitan las diferentes significaciones imaginarias encontradas a través del trabajo de campo, las cuales se identifican como de carácter instituido e instituyente (tabla 2).

Gracias al análisis de los datos se pudo identificar diversas características de lo imaginario social sobre naturaleza en los niños y niñas colaboradores del estudio:

El contexto en los imaginarios de los niños y las niñas

Los niños y niñas colaboradores viven en un sector que se caracteriza por tener aspectos de la ruralidad: se encuentran muy cerca al páramo y la mayoría de personas que viven allí provienen de familias campesinas cuyas prácticas se relacionan con la siembra y la crianza de animales de finca como vacas y gallinas de las que obtienen algún beneficio. A través de la información obtenida, vemos que prevalece este pensamiento de relación con la naturaleza de tipo tradicional campesino en las niñas y los niños, quienes dan muestra de una relación positiva y directa con la naturaleza y manifiestan sentimientos y emociones agradables frente a lo natural. Esto demuestra un pensamiento y relación instrumental enfocados en el sostenimiento de la familia y lejos de alguna intención productiva capitalista.

La familia, la escuela y los medios: fuente de imaginarios sobre naturaleza

Es evidente el papel determinante de la familia, la escuela y los medios de comunicación como instituciones sociales, socializadoras, en la construcción del niño y de la niña como sujetos de imaginarios sociales, de manera que las experiencias expresadas por ellos ocurrieron bajo el cuidado de sus familias o de la escuela o fueron vistos en la televisión. Las experiencias contadas por las niñas y los niños fueron organizadas por la familia de la que también cuentan cómo algunos de sus miembros realizan prácticas de siembra, "cuidan las plantas que tienen en sus casas" (Niño participante N. ${ }^{\circ}$ 2) y "tienen cuidado de no botar basura al pasto" (Niño participante N. ${ }^{\circ}$ 5). Acerca del colegio, el niño participante N. ${ }^{\circ} 1$ nos contó: "Ayer fuimos a plantar matas y las rociamos porque allá hay un jardín entonces es de nosotros entonces nosotros fuimos a plantar". Otros contaron que en clase de Artes dibujan animales y en Biología aprenden a clasificarlos. En cuanto a lo visto en televisión, los niños están enterados de que estamos en sequía y ven programas donde:

[...] unas personas que iban a diferentes bosques o islas del mundo y tenían que sobrevivir, tenían que saber cuáles plantas se podían comer, cuáles no, cuáles eran venenosas y aprender a armar un refugio en medio de la naturaleza y sobrevivir en medio de la naturaleza y las serpientes. (Niño participante N. ${ }^{\circ}$ )

\section{Significaciones imaginarias sobre naturaleza}

Los dibujos elaborados en el taller iconográfico develan el carácter identitario-conjuntista del término naturaleza, el cual evoca una serie de representaciones en común encontradas en el análisis iconográfico. Producto de la experiencia del niño y de la niña que han sido interiorizadas a través de un representar-decir de conjunto de una sociedad y que, desde temprana edad, se manifiesta en cada sujeto como determinante inconsciente de su relación con la naturaleza y lo natural. Como dice Castoriadis: 
Tabla 2. Rejilla de clasificación de significaciones imaginarias identificadas.

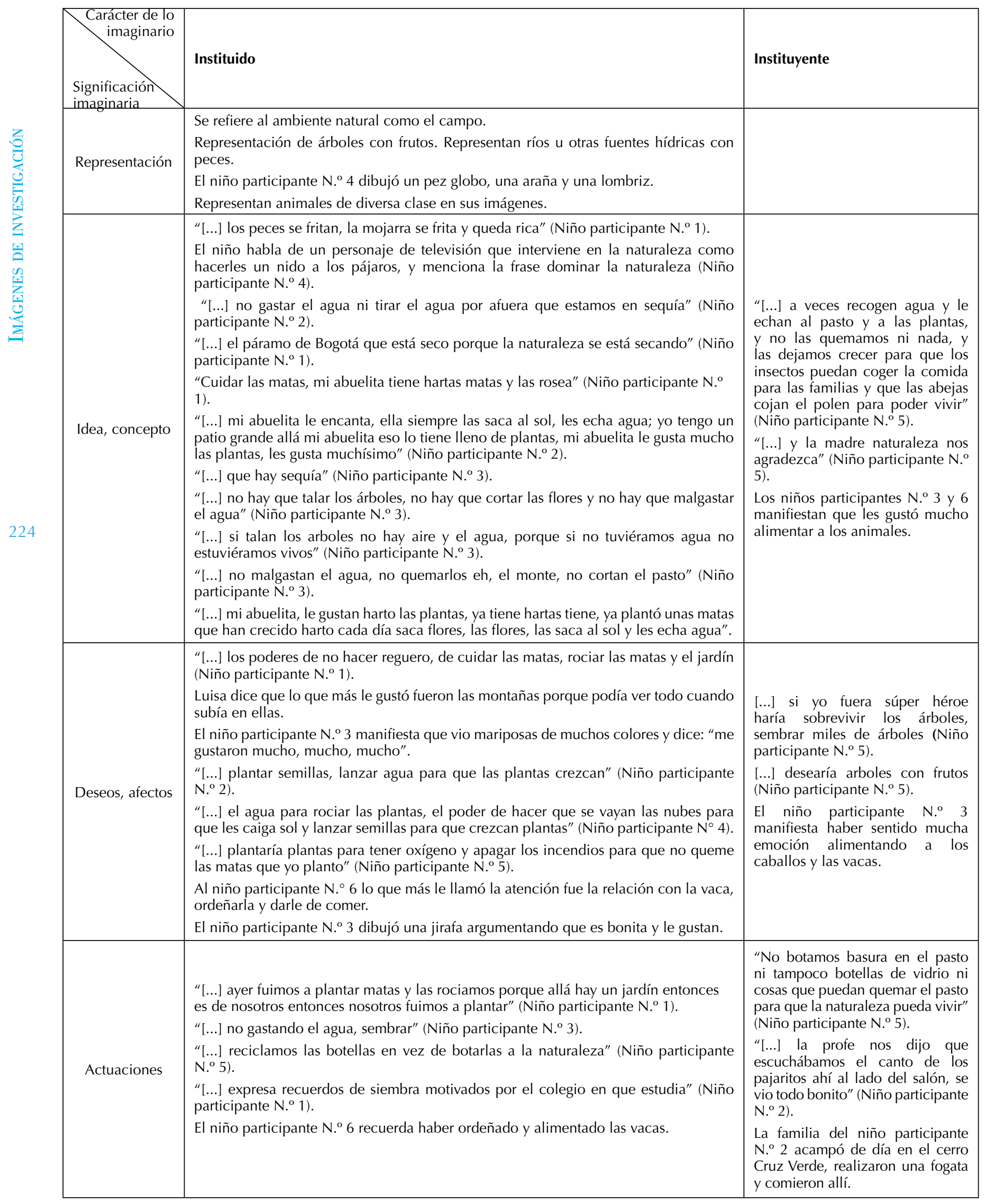


[...] en y por el legein y el teukheim se instrumenta la institución global de la sociedad, figuración-presentificación del magma de significaciones a que aquella da existencia en cada momento. Esta institución es en cada momento institución del mundo como mundo de esta sociedad y para esta sociedad, y como organización-articulación de la sociedad misma. (1983, p. 373)

Las ideas y conceptos encontradas en el estudio son muy variadas, sin embargo, muchos tienen que ver con ideas ya conocidas, aprendidas y apropiadas por los niños y las niñas de su sociedad. Algunos componentes de la naturaleza son claramente vistos como "recursos" al servicio del ser humano, y su atención hacia ellos está enfocada en el pensamiento de conservación y uso racional de lo natural por el mismo ser humano: los niños hablan de "no malgastar el agua porque estamos en sequía" (Niño participante N..$^{\circ}$ ); y en una oportunidad uno de los niños menciona que lo que más le gustó de la experiencia relatada fue "la mojarra, pues se cocina y queda rica" (Niño participante N.o 1). La preocupación por lo natural en estos niños y niñas está fuertemente ligado a su uso y servicio para bienestar del ser humano, de manera que expresan que si "talan los arboles no hay aire, y el agua porque si no tuviéramos agua no estuviéramos vivos" (Niño participante N..$^{\circ}$ ). Este pensamiento está relacionado con pensamientos antropocéntricos y de dominación de lo natural más que con alguna visión del planeta como un gran hábitat organizado y en equilibrio.

Pero, pese a la predominancia de estas ideas, se pudo encontrar, también, algunas expresiones relacionadas con la comprensión de las dinámicas ecosistémicas y su preocupación por ellas como necesarias para otros seres vivos como cuando un niño nos cuenta sobre las plantas: "las dejamos crecer para que los insectos puedan coger la comida para las familias y que las abejas cojan el polen para poder vivir" (Niño participante N. ${ }^{\circ}$ 5). Esto nos permite ver un pensamiento diferente al instrumentalista y que más bien se acerca a una comprensión de los sistemas naturales y la importancia de su existencia.

Los sentimientos, deseos y afectos expresados permiten afirmar que la naturaleza sigue siendo, por fortuna, un contexto que disfrutan los niños y el cual les brinda elementos poco usuales y de mucho interés para ellos que claramente carecen de todo valor en capital. Cuando se le preguntó a los niños sobre lo que les Ilamaba la atención, mencionaban aspectos propios de los ambientes naturales como el sonido de la cascada, las frutas en los árboles, el poder ver muchas cosas desde lo alto de las montañas, los colores de las flores, entre otros. Las narraciones obtenidas, frente a acciones que realizarían los niños por la naturaleza, dejan claro el conocimiento que ellos tienen de la crítica situación de los ambientes naturales y su deseo de mitigarla pues expresan que les gustaría tener el poder de "lanzar semillas para que crezcan plantas (Johan), apagar los incendios para que no queme las matas" (Niño participante N. ${ }^{\circ}$ ) o "no tumbar los árboles" (Niño participante N. ${ }^{\circ} 6$ ).

Desde las acciones narradas, como aspecto importante de las significaciones imaginarias sobre naturaleza encontramos, por un lado, manifestaciones de conservación y uso racional de lo natural visto como un recurso bajo acciones como "no malgastar el agua" (Niño participante N. ${ }^{\circ}$ 6). También se evidencian, en mayor medida, manifestaciones de restauración y prácticas conscientes de relación frente a lo natural como la siembra de semillas, el cuidado de las plantas y el reciclaje. Como un tercer tipo de significación, presentada en menos medida, se evidenció nuevamente la preocupación por la convivencia con los ecosistemas como cuando un niño dice que: "no botamos basura en el pasto ni tampoco botellas de vidrio ni cosas que puedan quemar el pasto para que la naturaleza pueda vivir" (Niño participante N. ${ }^{\circ} 5$ ).

Las acciones de los niños y las niñas muestran claramente una conciencia de respeto, cuidado y convivencia con lo natural. Sin embargo, lo manifiestan desde diversas perspectivas como complejos imaginarios latentes en sus respuestas que permiten ver cómo están presentes diferentes formas de ver la naturaleza. Estas van desde apreciarla como un valioso recurso al servicio del ser humano, el cual se debe administrar, hasta la visión del ser humano como responsable del equilibrio entre el aprovechamiento de lo natural como recurso y su restauración como ecosistema y hábitat de otros seres vivos. 
Develando imaginarios sobre naturaleza

Los niños nos hablan y cuentan de muchos aspectos sobre la naturaleza y lo que es para ellos en diferentes momentos y niveles. Cuando cuentan su dibujo, la representan como algo ajeno, un terreno inmenso de cosas bonitas a las que nos podemos acercar en ocasiones, interactuar con ella, comer de los frutos de los árboles, tocar el agua y a los peces, para luego regresar a casa. En ocasiones, la representaban como ese ser indefenso al que hay que cuidar y proteger como regar a la planta de la casa, alimentar la vaquita o sembrar muchos árboles. También la representaron como un recurso para uso del ser humano, como el agua que no debemos malgastar o los árboles sin los que no tendríamos oxígeno. Ellos logran comprender la complejidad del término naturaleza y nos dan a conocer cómo se relacionan con ella en diversos niveles de los que emergen sentimientos, pensamientos, recuerdos y un sin número de prácticas y discursos que desde cada sujeto contribuye a la relación de la sociedad con los entornos naturales.

Frente a la visión de naturaleza que han construido los niños y las niñas como sujetos sociales, manifestaron, en mayor medida, el imaginario de dominancia racional pues se pudo identificar la visión antropocéntrica en la que lo natural está allí para aprovechamiento y servicio del ser humano. Este imaginario predominante es alimentado desde el discurso y el hacer social en el que este sector de la infancia se encuentra inmersa. Pese a que se habla de una conciencia ambiental y un cambio de relación con la naturaleza, este pensamiento se sigue argumentando desde la subsistencia del ser humano gracias a los "recursos naturales" y no desde una comprensión de lo natural como sistema complejo, organizado y parte de una totalidad que entre muchas otras cosas, permite la continuidad de la vida en la tierra, entre la que se encuentra la vida del ser humano.

Los otros imaginarios también aparecieron en mínima medida. Se pudo identificar que, en los niños y las niñas colaboradores, uno de los imaginarios más manifestados frente a la situación ambiental actual es la defensa del patrimonio común con el que se "busca la protección y conservación de la naturaleza" (Ospina, 2008, p. 76), pues en repetidas ocasiones manifestaron significaciones relacionadas con el cuidado, conservación y no destrucción de lo natural. Este imaginario se manifiesta como una preocupación intrascendente por lo natural en la que los sujetos no demuestran interés alguno por transformar sus prácticas y relaciones de producción y consumo irracional sino más bien, minimizar o contrarrestar de algún modo el daño causado sin que esto afecte su estilo de vida. Los demás imaginarios, planteados por Ospina, como el de volver al primitivismo o construir un ideal de ecodesarrollo, no se manifiestan.

Lo anterior indica que, pese a que el contexto geográfico de estos niños y niñas es diferente y tiene unas particularidades que permite una relación más cercana con la naturaleza, los discursos y prácticas provenientes de las instituciones más influyentes en la construcción del niño como sujeto social expresan imaginarios instituidos que son apropiados con fuerza por la infancia de estos sectores, al punto en que no manifiestan importantes construcciones de lo imaginario con respecto a los espacios naturales dentro de donde viven.

\section{Conclusiones}

Los niños y niñas de Ciudad Londres tienen una relación cercana con lo natural, que les suscita significaciones positivas además de ser conscientes de la realidad ambiental actual mostrando preocupación por ello. Sin embrago, el grueso de sus imaginarios sobre naturaleza corresponde a lo instituido, proveniente de discursos y prácticas de la ciudad a través de la familia, la escuela y los medios de comunicación, en los que prevalecen pensamientos de antropocentrismo frente a la relación con lo natural, concibiéndolo al servicio del ser humano y/o bajo su cuidado y protección. Por otro lado, se lograron identificar también, aunque en una pequeña medi$\mathrm{da}$, algunos imaginarios instituyentes que hacen referencia a la comprensión de lo natural como parte de organizaciones ecosistémicas que permiten la vida de especies distintas al ser humano, y que no necesitan de su intervención si no, más bien, del respeto por su existencia tal cual es.

Los espacios naturales cercanos al barrio Ciudad Londres son una fortaleza para la educación ambiental y la construcción de imaginarios 
instituyentes sobre naturaleza pero, pese a esto, los niños y las niñas participantes se sienten ajenos a los mismos y los representan como espacios de disfrute esporádico. Las manifestaciones sobre lo natural son más cercanas a lo experimentado a través de los medios de comunicación o la escuela, experiencias que corresponden a otros contextos y están en contradicción, muchas veces, con el contexto real de estos niños y niñas. Ellos no manifestaron, de manera significativa, alguna relación entre los aprendizajes de la escuela y el contexto en el que viven.

La fuerza de los imaginarios radica en las experiencias que viven los sujetos desde que nacen, de manera que tales sujetos van edificando magmas de significaciones en su cotidianidad, de modo inconsciente y gracias a todo lo que experimentan a través de sus sentidos. Ante lo anterior, se comprende la importancia de que los profesionales en educación empecemos a resignificar nuestra relación con el medio ambiente, adquirir una conciencia crítica y propositiva frente a nuestras prácticas cotidianas en relación con el entorno natural para, de este modo, promover imaginarios instituyentes más coherentes con las necesidades del planeta, y todo ser vivo que lo habita, en nuestros tiempos actuales.

Es clara la importancia que juegan los medios de comunicación en la institución y reproducción del legein y el teukheim en los sujetos de la sociedad bogotana actual y que se traduce en prácticas y discursos con los que nos identificamos y damos existencia a una realidad, en este caso, de la relación entre el ser humano y lo natural, ignorando muchas otras maneras y posibilidades y concibiendo esta como único camino. Es una responsabilidad muy grande la que tenemos, como sociedad, y en ella, cada sujeto como profesional o como ser humano, en la tarea de construcción de un diferente representar/decir (legein) y un quehacer/técnica (teukheim) sociales que conlleven a la aparición de otras posibles formas de relación con lo natural y con todo lo demás.

\section{Referencias}

Boff, L. (2013). Ecología, grito de la tierra, grito de los pobres. Buenos Aires: Lumen.

Bonilla-Castro, E.; Rodríguez R. (1997). Más allá del dilema de los métodos: la investigación en Ciencias Sociales. Bogotá: Norma.

Castoriadis, C. (1983). La institución imaginaria de la sociedad. Barcelona: Tusquets.

Escobar, A. (1986). La invención del desarrollo en Colombia. Lecturas de Economía, 20, 9-35.

Gadotti, M. (2002). Pedagogía de la Tierra. México: Siglo xxı.

González, J. (2000). El paradigma interpretativo en la investigación social y educativa. Cuestiones Pedagógicas: Revista de Ciencias de la Educación, 15, 227-243.

Leff, E. (2007). Complejidad, racionalidad ambiental y diálogo de saberes: hacía una pedagogía ambiental. Desenvolvimiento e Meio Ambiente, 16, 11-19.

Letorneau, J. (2007). Cómo analizar un documento iconográfico. En: La caja de herramientas del joven investigador: guía de iniciación al trabajo intelectual (pp. 95-110). Medellín: La Carreta.

Ospina, L. (2008). Imaginarios ambientales: voces emergentes desde la vida cotidiana. Luna Azul, 26, 57-79.

Rincón, C. (2007). La formación de maestros y los imaginarios de infancia: reseña de una investigación. En: F. A. Santamaría; M. H. Barreto: Lenguaje y saberes infantiles (pp. 146-154). Bogotá: Universidad Distrital Francisco José de Caldas y Cátedra Unesco en Desarrollo del Niño.

Romão, J. E. (2002). Presentación, planetariedad. En: M. Gadotti, Pedagogía de la Tierra. México: Siglo xxI.

Santamaría, F.; Bothert, K. (2011). Relatos de niños y niñas: juegos de palabras que crean y recrean vivencias. Infancias Imágenes, 10(1), 66-73. 